\title{
Governance Mechanism for Global Greenhouse Gas Emissions: A Stochastic Differential Game Approach
}

\author{
Wei Yu ${ }^{1,2}$ and Baogui Xin ${ }^{1,3}$ \\ ${ }^{1}$ School of Management, Tianjin University, Tianjin 300072, China \\ ${ }^{2}$ Department of Mathematics, Tianjin Polytechnic University, Tianjin 300387, China \\ ${ }^{3}$ School of Economics and Management, Shandong University of Science and Technology, Qingdao 266590, China
}

Correspondence should be addressed to Baogui Xin; xin@tju.edu.cn

Received 31 January 2013; Revised 2 May 2013; Accepted 3 May 2013

Academic Editor: Wuquan Li

Copyright (C) 2013 W. Yu and B. Xin. This is an open access article distributed under the Creative Commons Attribution License, which permits unrestricted use, distribution, and reproduction in any medium, provided the original work is properly cited.

\begin{abstract}
Today developed and developing countries have to admit the fact that global warming is affecting the earth, but the fundamental problem of how to divide up necessary greenhouse gas reductions between developed and developing countries remains. In this paper, we propose cooperative and noncooperative stochastic differential game models to describe greenhouse gas emissions decision makings of developed and developing countries, calculate their feedback Nash equilibrium and the Pareto optimal solution, characterize parameter spaces that developed and developing countries can cooperate, design cooperative conditions under which participants buy the cooperative payoff, and distribute the cooperative payoff with Nash bargaining solution. Lastly, numerical simulations are employed to illustrate the above results.
\end{abstract}

\section{Introduction}

There seems to be rather compelling evidence that global warming is an issue that we seriously need to be concerned about today. One of the important facts on global warming is the result of greenhouse gases (GHGs) trapping heat and making the planet warmer. A GHG is one of several gases in an atmosphere that absorbs and emits infrared radiation in a planetary atmosphere. Many important GHGs are naturally occurring, such as water vapor, carbon dioxide, methane, nitrous oxide, and ozone, but others can also be added to the atmosphere by human activities, such as hydrofluorocarbons, perfluorocarbons, and sulfur hexafluoride. The United Nation's Intergovernmental Panel on Climate Change (IPCC) claims that the only way they can get their computerized climate models to produce the observed warming is with anthropogenic pollution. Undoubtedly, the problem of global warming has been arising for more than 150 years and will get worse as time goes on.

According to CDIAC, top 20 emitting countries by total fossil-fuel $\mathrm{CO}_{2}$ emissions for 2009 were China, the
United States, India, the Russian Federation, Japan, Germany, Iran, Canada, South Korea, South Africa, United Kingdom, Indonesia, Mexico, Saudi Arabia, Italy, Australia, Brazil, France, Poland, and Spain. Under the Kyoto Protocol of 2010, 37 developed countries and European Community commit themselves to a reduction of GHGs in the period of 2008-2012. The United States signed but did not ratify the protocol, and Canada withdrew from it in 2011. To respond to the extension of the Kyoto Protocol beyond 2012, several developed countries have communicated their intentions to set quantified economy-wide emission reduction targets up to 2020. From China's newest "12th Five-year Plan on Greenhouse Emission Control (Guofa [2011] No. 41)," China aims to reduce the carbon intensity by 17 percent by 2015 compared with 2010 levels, though it is still a developing country.

A lot of researchers have paid much attention to the problem of GHG emission reduction without game theory. Williams et al. [1] proposed a technology path to deep GHG emissions cuts by 2050. Bastianoni et al. [2] analyzed the problem of assigning responsibility for GHG emissions. 
Parton et al. [3] studied agriculture's role in cutting GHG emissions. Tol [4] presented the marginal costs of GHG emissions. Ansuategi and Escapa [5] analyzed the relationship between economic growth and GHG emissions.

Other researchers have employed game theory to study the pollution management, including GHG emission reduction. Van der Ploeg and de Zeeuw studied noncooperative and cooperative pollution strategies and outcomes in a transboundary pollution in $[6,7]$. Long [8] analyzed a twoplayer transboundary differential game. Rubio and Casino [9] show that it is necessary that the initial value of the stock of pollution to be higher than the cooperative solution stock. Yeung [10] presented a cooperative game of transboundary industrial pollution. Bahn and Haurie [11] designed equilibrium solutions with coupled constraints in dynamic games of greenhouse gas emissions abatement. Jørgensen et al. [12-14] designed a cooperative agreement which was time consistent, at no instant of time, no player or group of players wishes to defect from the agreement. Smala Fanokoa et al. [15] considered a two-player asymmetric differential game of pollution control. Breton et al. [16-18] proposed the differential game models to analyze joint implementation in environmental projects, one of the flexible mechanisms considered in the Kyoto Protocol. Petrosjan and Zaccour [19] studied time-consistent Shapley value allocation of pollution cost reduction. Dockner et al. [20] used differential games into economics and management science, including pollution management.

In fact, stock of GHGs not only depends on the amounts of GHG emission or natural absorption, but also is affected by the other stochastic factors, such as random climate, natural disaster, and man-made factor. So the stochastic differential game model should be more appropriate than the deterministic differential game model to describe the above problems.

In recent years, stochastic theory has been playing an important role in the study of in science, engineering, and sociology, such as multiobjective stochastic productiondistribution planning problem [21], stochastic stabilization and control [22-28], market portfolio problem in a jump diffusion market [29], partial information problem [30], dynamic stochastic route choice model [31], stochastic heat dynamics systems [32], and stochastic Fokker-Planck-type problems [33]. In particular, the stochastic differential game has been successfully applied into the economics and management. For example, Leong and Huang [34] developed a stochastic differential game of capitalism to analyze the role of uncertainty. Yeung and Petrosyan [35] presented a cooperative stochastic differential game of transboundary industrial pollution with two novel features and analyzed the pollution management in the framework. Wang and Ewald [36] developed a stochastic differential fishery game for a two-species fish population with ecological interaction. Taksar and Zeng [37] studied stochastic differential games between two insurance companies who employ reinsurance to reduce risk exposure.

The remainder of this paper is organized as follows. In Section 2, we propose cooperative and noncooperative stochastic differential game models to describe greenhouse gas emissions decision makings of developed and developing countries. In Section 3, we calculate feedback Nash equilibrium and the Pareto optimal solution, characterize parameter spaces that developed and developing countries can cooperate, and design cooperative conditions under which participants buy the cooperative payoff. In Section 4, numerical simulations are employed to illustrate the above results. In Section 5, we study the assign the cooperative payoff with Nash bargaining solution. Finally, conclusions in Section 6 close the paper.

\section{Stochastic Differential Game Models}

For the sake of simplicity, global countries emitting GHGs can be divided into two interest groups: developing countries and developed countries, which are, respectively, denoted by player 1 and player 2 . Inspired by $[8,15]$, we assume the two participants have asymmetric environmental behaviors, which mean player 1 is not affected by the pollution, while player 2 is affected by the pollution, or player 1 has no interest in sacrificing economic growth to reduce GHGs emission, whereas player 2 would like to take necessary measures to protect and improve the environment through GHG emission reduction. In order to clarify the above problem, we further assume the following.

(1) $q_{i}(t)$ is the output of player $i(i=1,2)$ with $t \epsilon$ $[0, \infty) . e_{i}(t)=h_{i}\left(q_{i}(t)\right)$ denotes the quantity of GHG emission of player i. $r_{i}\left(q_{i}(t)\right)$ represents net revenue of player $i$ with $q_{i}(t)$.

(2) $h_{i}\left(q_{i}(t)\right)$ is a strictly increasing function, that is, $(d / d q)\left(h_{i}\left(q_{i}(t)\right)\right)>0$. So we can denote $r_{i}\left(q_{i}(t)\right)=$ $r_{i}\left(h_{i}^{-1}\left(e_{i}(t)\right)\right)$ and $R_{i}\left(e_{i}(t)\right)=r_{i}\left(h_{i}^{-1}\left(e_{i}(t)\right)\right)$.

(3) $R_{i}\left(e_{i}(t)\right)$ is a monotonically increasing concave function of $e_{i}(t)$, that is, $R_{i}^{\prime}\left(e_{i}\right) \geq 0, R_{i}^{\prime \prime}\left(e_{i}\right) \geq 0, R_{i}(0)=$ $0 . s(t)$ is the stock of GHGs. $D_{i}(s(t))$ is a monotone increasing convex function of $s(t)$, which is the cost of player $i$ caused by the stock of GHGs $s(t)$.

(4) $\mu \geq 0$ is a constant that means the marginal impact on GHG emission. $\varepsilon>0$ is a natural absorption rate. Without loss of generality, we assume that the marginal impact of GHG emission on both players is the same. $\sigma \geq 0$ is a constant affected by the weather, natural disasters, human factors, unpredictable factors, and so on. $B(t)$ is a Wiener process.

(5) Player $i$ will, even if alone, maximize its expected payoff in case no agreement is reached between both players.

According to the above assumptions, we get cooperative and noncooperative stochastic differential game models for asymmetric GHG emission problems over an infinite horizon. 


\subsection{Noncooperative Stochastic Differential Game Model.}

Consider

$$
\begin{array}{r}
d s(t)=\left(\mu\left(e_{1}(t)+e_{2}(t)\right)-\varepsilon s(t)\right) d t+\sigma s(t) d B(t), \\
s(0)=s_{0} \\
J_{i}=\max _{e_{i}} E\left\{\int_{0}^{\infty} e^{-r t}\left(R_{i}\left(e_{i}(t)\right)-D_{i}(s(t))\right) d t\right\}, \\
i=1,2,
\end{array}
$$

where $s_{0}$ is the initial GHGs stock with $t=0, r$ is the discount rate, and $e^{-r t}$ is the discount factor.

Without consensus agreement between both players, they will, alone, maximize their payoffs as follows:

$$
\begin{gathered}
J_{1}=\max _{e_{1}} E\left(\int_{0}^{\infty} e^{-r t} R_{1}\left(e_{1}(t)\right) d t\right), \\
J_{2}=\max _{e_{2}} E\left\{\int_{0}^{\infty} e^{-r t}\left(R_{2}\left(e_{2}(t)\right)-D_{2}(s(t))\right) d t\right\},
\end{gathered}
$$

which mean that player 1 maximizes its payoffs through its industrial activities without internalizing the damage of GHGs emission on the basis of (3), and player 2 maximizes its payoff based on (4).

We use $\Gamma\left(s_{0}, \infty-0\right)$ to denote the noncooperative stochastic differential game Equations (1) and (3) and (1) and (4). In addition, we use $\Gamma\left(s_{\tau}, \infty-\tau\right)$ to represent the above game with the initial state $s_{\tau} \in S$ and the time $\tau \in[0, \infty)$.

The rational economic explanation for the noncooperative game is that (3) is the payoff of player 1 and implies its prior strategy of economic development, which means that developing countries will always maximize their economic benefit rather than give environmental protection a high priority.

2.2. Cooperative Stochastic Differential Game Model. In order to reach a cooperative agreement of GHG emission, we adopt a cooperative stochastic differential game to get its Nash equilibrium, that is, a cooperative agreement, which is a solution concept of a cooperative game involving two players, such that no player has an incentive to unilaterally change its GHG emission decision. In other words, players are in an equilibrium if a GHG emission decision change in strategies by any one of them would lead that player to earn less than if it remained with its current GHG emission strategy [38]. Two players' joint payoff is

$$
\begin{aligned}
J_{1} & +J_{2} \\
& =\max _{e_{1}, e_{2}} E\left\{\sum_{i=1}^{2} \int_{0}^{\infty} e^{-r t}\left(R_{i}\left(e_{i}(t)\right)-D_{i}(s(t))\right) d t\right\} .
\end{aligned}
$$

We use $\Psi\left(s_{0}, \infty-0\right)$ to denote the cooperative stochastic differential game Equations (1) and (5). In addition, we use $\Psi\left(s_{\tau}, \infty-\tau\right)$ to represent the above game with the initial state $s_{\tau} \in S$ and the time $\tau \in[0, \infty)$.

\section{Resolving Models}

In order to reduce the difficulty of mathematical handling, we assume that $R_{i}\left(e_{i}(t)\right)$ is a quadratic function of $e_{i}(t), i=$ 1,2 , and $D_{i}(s(t))$ is a quadratic function of $s(t)$, and cost parameters $\beta_{2} \geq \beta_{1} \geq 0$. Consider

$$
\begin{gathered}
R_{i}\left(e_{i}(t)\right)=\alpha_{i} e_{i}(t)-\frac{1}{2} e_{i}(t)^{2}, \quad i=1,2, \\
D_{i}(s(t))=\frac{1}{2} \beta_{i} s^{2}(t), \quad i=1,2,
\end{gathered}
$$

$\alpha_{i}>0, i=1,2$ and $\beta_{i} \geq 0, i=1,2$ are constants.

\subsection{Noncooperative Game}

\subsubsection{Noncooperative Game Solutions}

Definition 1. When the state variable $s(t)=s_{t}$, the value function $V^{(\tau) i}\left(t, s_{t}\right), i=1,2$ of a Nash equilibrium for the noncooperation stochastic differential game $\Gamma\left(s_{\tau}, \infty-\tau\right)$, that is, the current value of the expected payoff for player $i, i=1,2$ with the interval $[t, \infty)$ is given by

$$
V^{(\tau) i}\left(t, s_{t}\right)=E\left\{\int_{t}^{\infty} e^{-r(y-\tau)}\left(R_{i}\left(e_{i}(y)\right)-D_{i}(s(y))\right) d y\right\},
$$

for $\tau \in[0, \infty), t \in[\tau, \infty), i=1,2$.

Theorem 2 (see [39]). The strategy $\left\{\phi_{1}^{*}(t), \phi_{2}^{*}(t)\right\}$ is a feedback Nash equilibrium solution to the game $\Gamma\left(s_{0}, \infty-0\right)$. If there exist continuous functions $V_{i}(s): R \rightarrow R, i=1,2$ and continuous derivatives $V_{i}^{\prime}(s), V_{i}^{\prime \prime}(s), i=1,2$ satisfy the following Hamilton-Jacobi-Bellman equation:

$$
\begin{aligned}
& r V_{i}(s)-\frac{\sigma^{2} s^{2}}{2} V_{i}^{\prime \prime}(s) \\
&=\max _{e_{i}}\left\{\alpha_{i} e_{i}(t)-\frac{1}{2} e_{i}^{2}(t)-\frac{1}{2} \beta_{i} s^{2}(t)\right. \\
&\left.\quad+V_{i}^{\prime}(s)\left(\mu\left(e_{i}(t)+\phi_{j}^{*}(t)\right)-\varepsilon s(t)\right)\right\},
\end{aligned}
$$

where $\phi_{j}^{*}(t), j=1,2$ is the optimal control of the player $j, j=$ 1,2 .

Theorem 3. If above conditions are satisfied, its feedback Nash equilibrium is

$$
\begin{gathered}
e_{1}^{N}(t)=\alpha_{1}, \\
e_{2}^{N}=\alpha_{2}+\mu V_{2}^{\prime}(s)=\alpha_{2}+\mu\left(A_{2} s+B_{2}\right),
\end{gathered}
$$

where

$$
\begin{gathered}
A_{2}=\frac{\left(r+2 \varepsilon-\sigma^{2}\right)-\sqrt{\left(r+2 \varepsilon-\sigma^{2}\right)^{2}+4 \beta_{2} \mu^{2}}}{2 \mu^{2}}<0, \\
B_{2}=\frac{\left(\alpha_{1}+\alpha_{2}\right) \mu A_{2}}{r+\varepsilon-\mu^{2} A_{2}}<0 .
\end{gathered}
$$


Proof. For player 1,

$$
\begin{aligned}
& r V_{1}(s)-\frac{\sigma^{2} s^{2}}{2} V_{1}^{\prime \prime}(s) \\
&=\max _{e_{1}}\left\{\alpha_{1} e_{1}(t)-\frac{1}{2} e_{1}^{2}(t)\right. \\
&\left.\quad+V_{1}^{\prime}(s)\left(\mu\left(e_{1}(t)+\phi_{2}^{*}(t)\right)-\varepsilon s(t)\right)\right\} .
\end{aligned}
$$

Differentiating (11) with respect to $e_{1}$ and using extreme conditions, we can get

$$
e_{1}^{*}(t)=\alpha_{1}+\mu V_{1}^{\prime}(s)
$$

For player 2,

$$
\begin{aligned}
& r V_{2}(s)-\frac{\sigma^{2} s^{2}}{2} V_{2}^{\prime \prime}(s) \\
&=\max _{e_{2}}\left\{\alpha_{2} e_{2}(t)-\frac{1}{2} e_{2}^{2}(t)-\frac{1}{2} \beta_{2} s^{2}(t)\right. \\
&\left.+V_{2}^{\prime}(s)\left(\mu\left(e_{2}(t)+\phi_{1}^{*}(t)\right)-\varepsilon s(t)\right)\right\} .
\end{aligned}
$$

Differentiating (13) with respect to $e_{2}$ and using the extreme value theorem, we can get

$$
e_{2}^{*}(t)=\alpha_{2}+\mu V_{2}^{\prime}(s)
$$

Substituting $e_{1}^{*}(t), e_{2}^{*}(t)$ to (11),

$$
\begin{aligned}
r V_{1}(s) & -\frac{\sigma^{2} s^{2}}{2} V_{1}^{\prime \prime}(s) \\
= & \alpha_{1}\left(\alpha_{1}+\mu V_{1}^{\prime}(s)\right)-\frac{1}{2}\left(\alpha_{1}+\mu V_{1}^{\prime}(s)\right)^{2} \\
& +V_{1}^{\prime}(s)\left(\mu\left(\alpha_{1}+\mu V_{1}^{\prime}(s)+\alpha_{2}+\mu V_{2}^{\prime}(s)\right)-\varepsilon s(t)\right)
\end{aligned}
$$

hence, $V_{1}(s)=A_{1}, e_{1}^{*}(t)=\alpha_{1}, A_{1}=\alpha_{1}^{2} / 2 r$.

Substituting $e_{1}^{*}(t)$ and $e_{2}^{*}(t)$ to (13),

$$
\begin{aligned}
r V_{2}(s) & -\frac{\sigma^{2} s^{2}}{2} V_{2}^{\prime \prime}(s) \\
= & \alpha_{2}\left(\alpha_{2}+\mu V_{2}^{\prime}(s)\right)-\frac{1}{2}\left(\alpha_{1}+\mu V_{1}^{\prime}(s)\right)^{2}-\frac{1}{2} \beta_{2} s^{2} \\
& +V_{2}^{\prime}(s)\left(\mu\left(\alpha_{1}+\mu V_{1}^{\prime}(s)+\alpha_{2}+\mu V_{2}^{\prime}(s)\right)-\varepsilon s(t)\right),
\end{aligned}
$$

hence, $V_{2}(s)=(1 / 2) A_{2} s^{2}+B_{2} s+C_{2}, V_{2}^{\prime}(s)=A_{2} s+B_{2}, V_{2}^{\prime \prime}(s)=$ $A_{2}$.

As [40], we have

$$
\begin{gathered}
A_{2}=\frac{\left(r+2 \varepsilon-\sigma^{2}\right)-\sqrt{\left(r+2 \varepsilon-\sigma^{2}\right)^{2}+4 \beta_{2} \mu^{2}}}{2 \mu^{2}}<0, \\
B_{2}=\frac{\left(\alpha_{1}+\alpha_{2}\right) \mu A_{2}}{r+\varepsilon-\mu^{2} A_{2}}<0, \\
C_{2}=\frac{\alpha_{2}^{2}+2 \mu \alpha_{1} B_{2}+2 \mu \alpha_{2} B_{2}+\mu^{2} B_{2}^{2}}{2 r}
\end{gathered}
$$

hence, $e_{2}^{N}=\alpha_{2}+\mu V_{2}^{\prime}(s)=\alpha_{2}+\mu\left(A_{2} s+B_{2}\right)$.
Remark 4. (1) The first-order extreme value conditions show that player 2 determines its GHG emissions whose marginal profit $\left(\alpha_{2}-e_{2}\right)$ is equal to marginal cost $-\mu V_{2}^{\prime}(s)=-\mu\left(A_{2} s+\right.$ $\left.B_{2}\right)$. Since $V_{2}^{\prime}(s)=A_{2} s+B_{2}<0$, if $e_{2}^{N}=\alpha_{2}+\mu V_{2}^{\prime}(s)=$ $\alpha_{2}+\mu\left(A_{2} s+B_{2}\right) \Leftrightarrow \alpha_{2}>-\mu\left(A_{2} s+B_{2}\right)$, the feedback Nash equilibrium is interior.

(2) From Theorem 3, one can know that the feedback Nash equilibrium strategy $\left\{e_{1}^{N}(t), e_{2}^{N}(t)\right\}$ possesses the Markov property, because it depends only upon the present state, not on the sequence of events that preceded it.

(3) Theorem 3 shows that optimal strategies of the subgame and the original game are the same at the same time and conditions.

The individual gross payoff in the noncooperative game can be written as

$$
\begin{gathered}
W_{1}^{N}=V_{1}\left(s_{0}\right)=\frac{\alpha_{1}^{2}}{2 r}, \\
W_{2}^{N}=V_{2}\left(s_{0}\right)=\frac{1}{2} A_{2} s_{0}{ }^{2}+B_{2} s_{0}+C_{2} .
\end{gathered}
$$

From Definition 1, one can obtain

$$
\begin{aligned}
& V^{(\tau) i}\left(t, s_{t}\right) \\
& \quad=E\left\{\int_{t}^{\infty} e^{-r(y-\tau)}\left(R_{i}\left(e_{i}(y)\right)-D_{i}(s(y))\right) d y\right\} \\
& \quad=e^{-r(t-\tau)} E\left\{\int_{t}^{\infty} e^{-r(y-t)}\left(R_{i}\left(e_{i}(y)\right)-D_{i}(s(y))\right) d y\right\} \\
& =e^{-r(t-\tau)} V^{(t) i}\left(t, s_{t}\right) .
\end{aligned}
$$

Remark 5. For player $i, i=1,2$ in the noncooperative stochastic differential game $\Gamma\left(s_{\tau}, \infty-\tau\right)$ with the state variable $s(t)=s_{t}$; the discounted value of the subgame value function is equal to the current value of the expected payoff at the time $t \in[t, \infty)$.

\subsubsection{The Expected Stock and Its Limitation}

Theorem 6. The expectation stock and its limit in noncooperative game feedback Nash equilibrium satisfy

$$
\begin{gathered}
E s(t)=s_{0} e^{\left(\mu^{2} A_{2}-\varepsilon\right) t}+\frac{\mu \alpha_{1}+\mu \alpha_{2}+\mu^{2} B_{2}}{\varepsilon-\mu^{2} A_{2}}\left(1-e^{\left(\mu^{2} A_{2}-\varepsilon\right) t}\right), \\
\lim _{t \rightarrow \infty} E s(t)=\frac{\mu \alpha_{1}+\mu \alpha_{2}+\mu^{2} B_{1}}{\varepsilon-\mu^{2} A_{2}} .
\end{gathered}
$$

Proof. Substituting $e_{1}(t), e_{2}(t)$ to (1) leads to

$$
d s(t)=\left(\mu \alpha_{1}+\mu \alpha_{2}+\mu^{2} B_{2}+\left(\mu^{2} A_{2}-\varepsilon\right) s\right) d t+\sigma s d B(t) .
$$


Solving the above stochastic differential equation leads to

$$
\begin{aligned}
s(t)= & s_{0} e^{\left(\mu^{2} A_{2}-\varepsilon-(1 / 2) \sigma^{2}\right) t+\sigma B(t)} \\
& +\int_{0}^{t}\left(\mu \alpha_{1}+\mu \alpha_{2}+\mu^{2} B_{2}\right) \\
& \quad \times e^{\left(\mu^{2} A_{2}-\varepsilon-(1 / 2) \sigma^{2}\right)(t-\tau)+\sigma(B(t)-B(\tau))} d \tau,
\end{aligned}
$$

whose expectation is

$$
\begin{gathered}
E s(t)=E\left\{s_{0} e^{\left(\mu^{2} A_{2}-\varepsilon-(1 / 2) \sigma^{2}\right) t+\sigma B(t)}\right\} \\
+E\left\{\int_{0}^{t}\left(\mu \alpha_{1}+\mu \alpha_{2}+\mu^{2} B_{2}\right)\right. \\
\left.\quad \times e^{\left(\mu^{2} A_{2}-\varepsilon-(1 / 2) \sigma^{2}\right)(t-\tau)+\sigma(B(t)-B(\tau))} d \tau\right\} \\
=s_{0} e^{\left(\mu^{2} A_{2}-\varepsilon\right) t}+\frac{\mu \alpha_{1}+\mu \alpha_{2}+\mu^{2} B_{2}}{\varepsilon-\mu^{2} A_{2}}\left(1-e^{\left(\mu^{2} A_{2}-\varepsilon\right) t}\right) .
\end{gathered}
$$

Since $A_{2}<0$ and $\mu^{2} A_{2}-\varepsilon<0$ hold, one can obtain $\lim _{t \rightarrow \infty} E s(t)=\left(\mu \alpha_{1}+\mu \alpha_{2}+\mu^{2} B_{1}\right) /\left(\varepsilon-\mu^{2} A_{2}\right)$.

\subsection{Cooperative Game}

\subsubsection{Cooperative Game Solutions}

Theorem 7 (see [39]). The strategy $\left\{\varphi_{1}^{*}(t), \varphi_{2}^{*}(t)\right\}$ is a Pareto optimal solution to the game $\Psi\left(s_{0}, \infty-0\right)$, if there exist continuous function $W_{i}(s): R \rightarrow R$ and continuous derivatives $W_{i}^{\prime}(s), W_{i}^{\prime \prime}(s) ; i=1,2$ satisfy the following Hamilton-JacobiBellman equation:

$$
\begin{aligned}
& r W(s)-\frac{\sigma^{2} s^{2}}{2} W^{\prime \prime}(s) \\
&=\max _{e_{1}, e_{2}}\left\{\sum_{i=1}^{2}\left(\alpha_{i} e_{i}(t)-\frac{1}{2} e_{i}^{2}(t)-\frac{1}{2} \beta_{i} s^{2}(t)\right)\right. \\
&\left.+W^{\prime}(s)\left(\mu\left(e_{i}(t)+\varphi_{j}^{*}(t)\right)-\varepsilon s(t)\right)\right\} .
\end{aligned}
$$

Hence, the players will adopt the cooperative control $\left\{\varphi_{1}^{*}(t), \varphi_{2}^{*}(t)\right\}$ characterized in Theorem 7 .

Theorem 8. The Pareto optimal solution of the cooperative stochastic differential game $\Psi\left(s_{0}, \infty-0\right)$ is given by

$$
e_{i}=\alpha_{i}+\mu W^{\prime}(s)=\alpha_{i}+\mu(a s+b), \quad i=1,2,
$$

where

$$
\begin{gathered}
a=\frac{\left(r+2 \varepsilon-\sigma^{2}\right)-\sqrt{\left(r+2 \varepsilon-\sigma^{2}\right)^{2}+8 \mu^{2}\left(\beta_{1}+\beta_{2}\right)}}{4 \mu^{2}}<0, \\
b=\frac{\mu\left(\alpha_{1}+\alpha_{2}\right) a}{r+\varepsilon-2 \mu^{2} a}<0 .
\end{gathered}
$$

Proof. Differentiating (24) with respect to $e_{i}$ and using extreme value conditions, one can get

$$
e_{i}=\alpha_{i}+\mu W^{\prime}(s), \quad i=1,2
$$

Using $e_{i}=\alpha_{i}+\mu W^{\prime}(s), i=1,2$ into (24), one can obtain

$$
\begin{aligned}
r W(s) & -\frac{\sigma^{2} s^{2}}{2} W^{\prime \prime}(s) \\
= & \frac{1}{2}\left(\alpha_{1}+\mu W^{\prime}(s)\right)^{2}+\frac{1}{2}\left(\alpha_{2}+\mu W^{\prime}(s)\right)^{2} \\
& -\frac{1}{2}\left(\beta_{1}+\beta_{2}\right) s^{2}-\varepsilon s W^{\prime}(s)
\end{aligned}
$$

From the above equation, it is rational to assume $W(s)$ is a quadratic polynomial.

Let $W(s)=(1 / 2) a s^{2}+b s+c$, one can get $2 \mu^{2} a^{2}-(r+2 \varepsilon-$ $\left.\sigma^{2}\right) a-\left(\beta_{1}+\beta_{2}\right)=0$.

As [40], we have

$$
\begin{gathered}
a=\frac{\left(r+2 \varepsilon-\sigma^{2}\right)-\sqrt{\left(r+2 \varepsilon-\sigma^{2}\right)^{2}+8 \mu^{2}\left(\beta_{1}+\beta_{2}\right)}}{4 \mu^{2}}<0, \\
b=\frac{\mu\left(\alpha_{1}+\alpha_{2}\right) a}{r+\varepsilon-2 \mu^{2} a}<0, \\
c=\frac{\left(\alpha_{1}+\mu b\right)^{2}+\left(\alpha_{2}+\mu b\right)^{2}}{2 r}>0 .
\end{gathered}
$$

Hence, $e_{i}=\alpha_{i}+\mu W^{\prime}(s)=\alpha_{i}+\mu(a s+b), i=1,2$.

Remark 9. (1) The Pareto optimal solution $\left\{e_{1}, e_{2}\right\}$ possesses the Markov property.

(2) Theorem 8 shows that Pareto optimal solutions of the subgame and the original game are the same at the same time and conditions.

The cooperative value function is given by $W^{C}(s)=$ $(1 / 2) a s^{2}+b s+c$, where

$$
\begin{gathered}
a=\frac{r+2 \varepsilon-\sigma^{2}-\sqrt{\left(r+2 \varepsilon-\sigma^{2}\right)^{2}+8 \mu^{2}\left(\beta_{1}+\beta_{2}\right)}}{4 \mu^{2}}<0, \\
b=\frac{\mu\left(\alpha_{1}+\alpha_{2}\right) a}{r+\varepsilon-2 \mu^{2} a}<0, \\
c=\frac{\left(\alpha_{1}+\mu b\right)^{2}+\left(\alpha_{2}+\mu b\right)^{2}}{2 r}>0 .
\end{gathered}
$$




\subsubsection{The Expected Stock and Its Limitation}

Theorem 10. The expectation stock and its limit in the Pareto optimal solution of the cooperative stochastic differential game $\Psi\left(s_{0}, \infty-0\right)$ satisfy

$$
\begin{gathered}
E s^{C}(t)=s_{0} e^{\left(2 \mu^{2} a-\varepsilon\right) t}+\frac{\mu \alpha_{1}+\mu \alpha_{2}+2 \mu^{2} a}{\varepsilon-\mu^{2} a}\left(1-e^{\left(2 \mu^{2} a-\varepsilon\right) t}\right), \\
\lim _{t \rightarrow \infty} E s^{C}(t)=\frac{\mu \alpha_{1}+\mu \alpha_{2}+2 \mu^{2} b}{\varepsilon-2 \mu^{2} a}
\end{gathered}
$$

Proof. Substituting $e_{1}(t), e_{2}(t)$ to (1) leads to

$$
\begin{aligned}
d s^{C}(t)= & \left(\mu\left(\alpha_{1}+\mu\left(a s^{C}(t)+b\right)+\alpha_{2}+\mu\left(a s^{C}(t)+b\right)\right)\right. \\
& \left.-\varepsilon s^{C}(t)\right) d t+\sigma s^{C}(t) d B(t) \\
= & \left(\mu \alpha_{1}+2 \mu^{2} b+\mu \alpha_{2}+\left(2 \mu^{2} a-\varepsilon\right) s^{C}(t)\right) d t \\
& +\sigma s^{C}(t) d B(t) .
\end{aligned}
$$

Solving the above stochastic differential equation leads to

$$
\begin{aligned}
s^{C}(t)= & s_{0} e^{\left(2 \mu^{2} a-\varepsilon-(1 / 2) \sigma^{2}\right) t+\sigma B(t)} \\
& +\int_{0}^{t}\left(\mu \alpha_{1}+\mu \alpha_{2}+2 \mu^{2} b\right) \\
& \quad \times e^{\left(2 \mu^{2} a-\varepsilon-(1 / 2) \sigma^{2}\right)(t-\tau)+\sigma(B(t)-B(\tau))} d \tau .
\end{aligned}
$$

Taking the expectation of the above equation leads to

$$
\begin{aligned}
E s^{C}(t)= & E\left\{s_{0} e^{\left(2 \mu^{2} a-\varepsilon-(1 / 2) \sigma^{2}\right) t+\sigma B(t)}\right\} \\
& +E\left\{\int_{0}^{t}\left(\mu \alpha_{1}+\mu \alpha_{2}+2 \mu^{2} b\right)\right. \\
& \left.\times e^{\left(2 \mu^{2} a-\varepsilon-(1 / 2) \sigma^{2}\right)(t-\tau)+\sigma(B(t)-B(\tau))} d \tau\right\} \\
= & s_{0} e^{\left(2 \mu^{2} a-\varepsilon\right) t}+\frac{\mu \alpha_{1}+\mu \alpha_{2}+2 \mu^{2} a}{\varepsilon-\mu^{2} a}\left(1-e^{\left(2 \mu^{2} a-\varepsilon\right) t}\right) .
\end{aligned}
$$

Since $a<0$ and $2 \mu^{2} a-\varepsilon<0$ hold, one can get $\lim _{t \rightarrow \infty} E s^{C}(t)=\left(\mu \alpha_{1}+\mu \alpha_{2}+2 \mu^{2} b\right) /\left(\varepsilon-2 \mu^{2} a\right)$.

\section{Numerical Simulations}

4.1. Noncooperative Game. Let $r=0.05, \sigma=0.2, \varepsilon=0.3$, $s_{0}=0.5, \beta_{1}=0.2, \beta_{2}=0.25, \alpha_{1}=2, \alpha_{2}=3$, and $\mu=0.8$. For player 2, its noncooperative feedback Nash equilibrium $e_{2}^{N}$, as shown in Figures 1,2 , and 3, increases with $\varepsilon$ but decreases with either $s$ or $\sigma$ or $\beta_{2}$. To be specific, the optimal quantity of GHG emission of player 2 is proportional to the natural absorption rate and inversely proportional to the

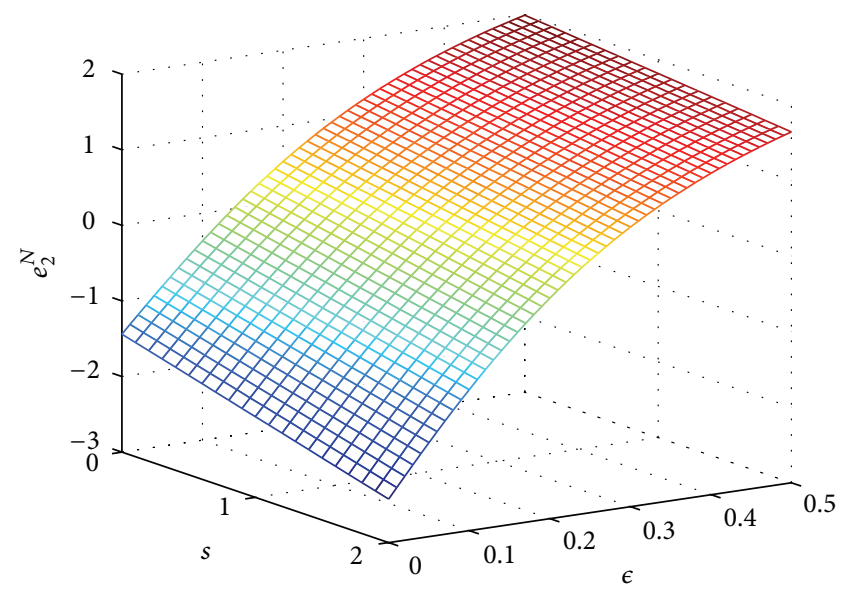

Figure 1: $e_{2}^{N}$ versus $s$ and $\varepsilon$.

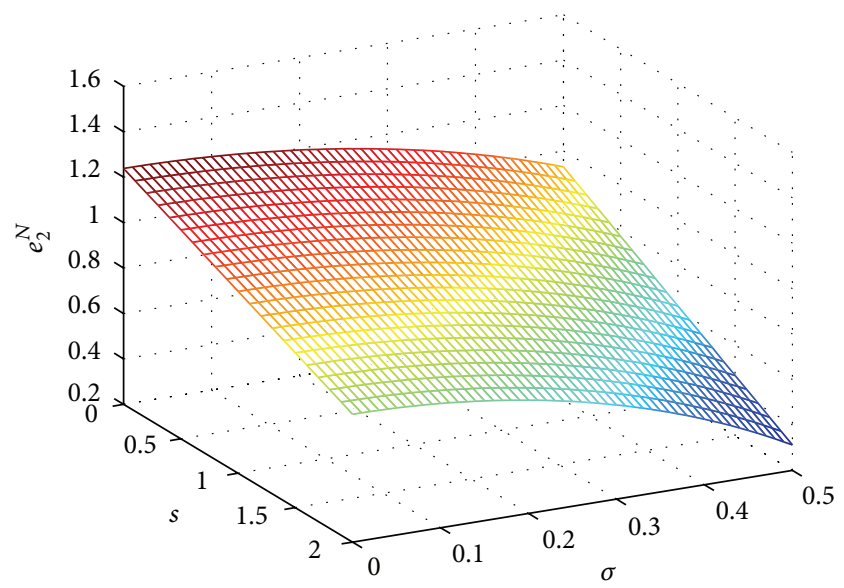

FIGURE 2: $e_{2}^{N}$ versus $s$ and $\sigma$.

stock of GHGs and constant affected by stochastic factors and cost parameter of player 2. Its limitation of GHG stock $\lim _{t \rightarrow \infty} E s^{N}(t)=5.1297$ is shown in Figure 4. For the sake of simplicity, in this section we denote $E V_{2}(s)$ as $V_{2}(s)$. Its expected profit $E V_{2}(s)$ increases with $\varepsilon$ but decreases with either $\sigma$ or $\beta_{2}$ and changes little with $s$ shown in Figures 5, 6 , and 7. More specifically, the expected profit is proportional to the natural absorption rate, is inversely proportional to constant affected by stochastic factors and cost parameter of player 2, and has little to do with the stock of GHGs.

4.2. Cooperative Game Situation. Let $r=0.05, \sigma=0.2, \varepsilon=$ $0.3, s_{0}=0.5, \beta_{1}=0.2, \beta_{2}=0.25, \alpha_{1}=2, \alpha_{2}=3$, and $\mu=0.8$. For player 1 and player 2 , their Pareto optimal solutions $e_{1}$ and $e_{2}$, as shown in Figures $8,9,10,11,12,13,14$, and 15, and their GHG emissions both increase with $\varepsilon$ but decrease with $s$ or $\sigma$ or $\beta_{1}$ or $\beta_{2}$. Practically speaking, the optimal quantities of GHG emissions of player 1 and player 2 are all proportional 


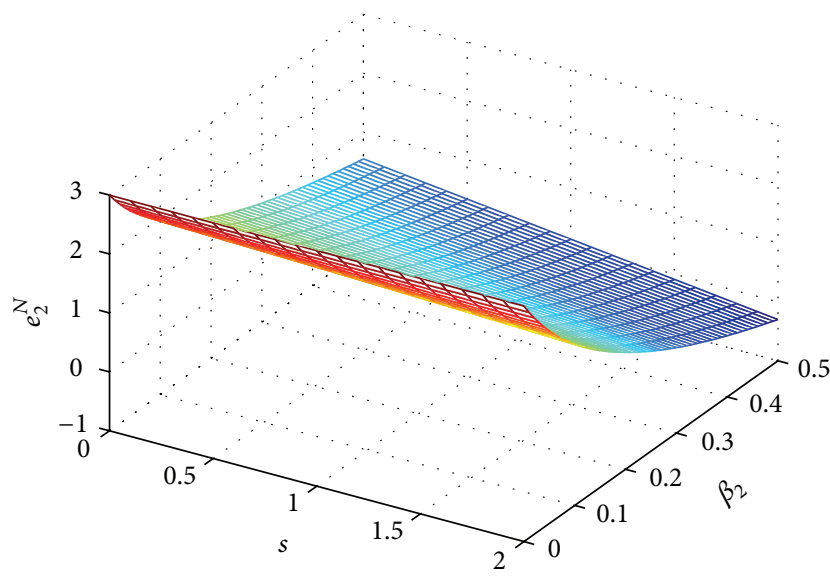

Figure 3: $e_{2}^{N}$ versus $s$ and $\beta_{2}$.

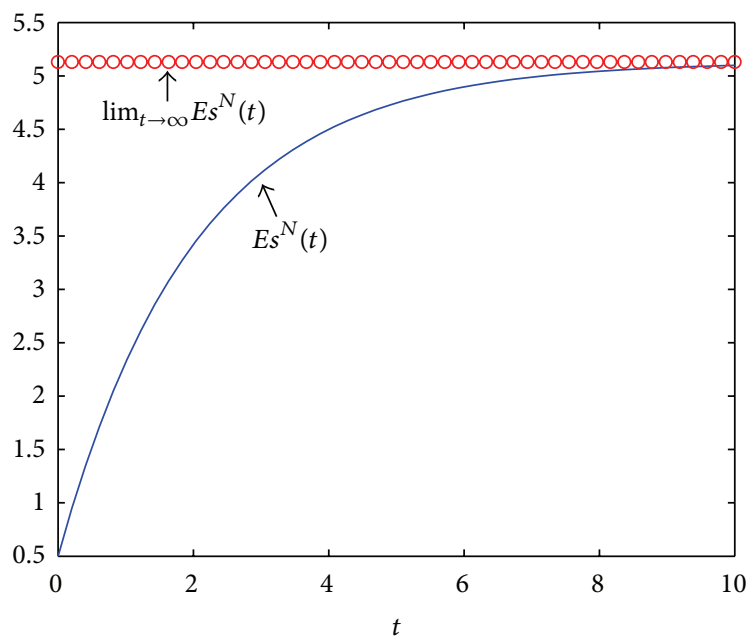

FIgURE 4: $E s^{N}(t)$ and $\lim _{t \rightarrow \infty} E s^{N}(t)$ versus $t$.

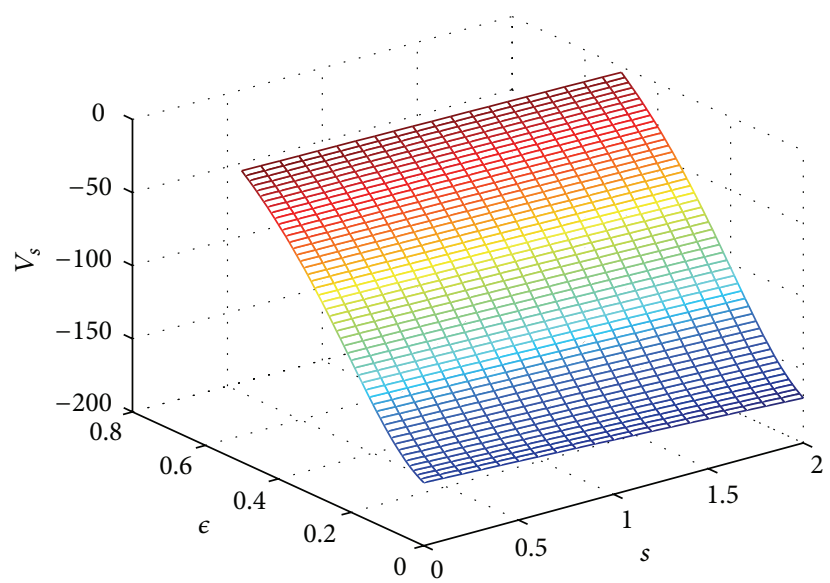

FIGURE 5: $V_{2}(s)$ versus $s$ and $\varepsilon$.

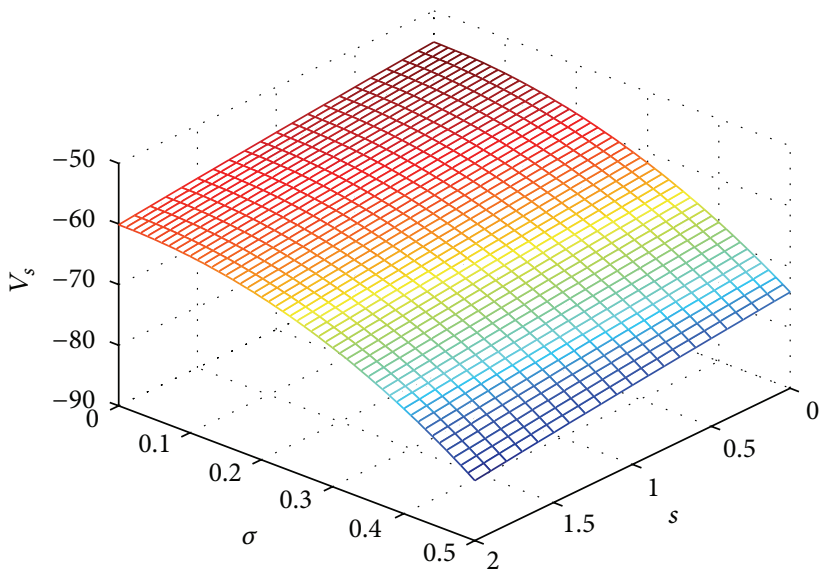

Figure 6: $V_{2}(s)$ versus $s$ and $\sigma$.

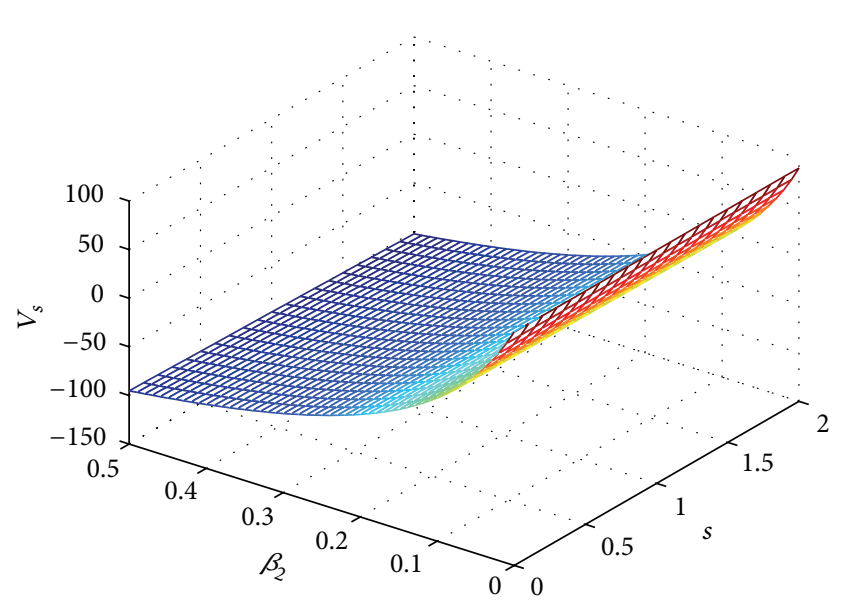

Figure 7: $V_{2}(s)$ versus $s$ and $\beta_{2}$.

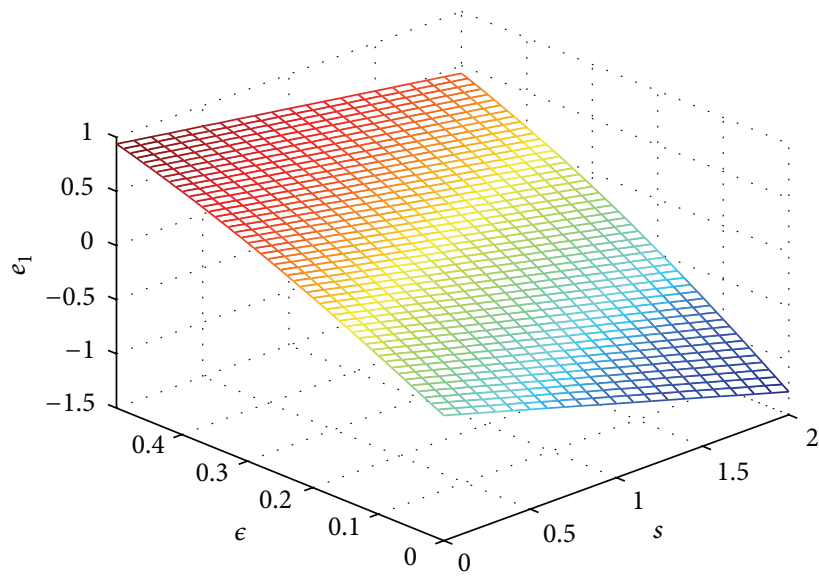

FIGURE 8: $e_{1}$ in terms of $s$ and $\varepsilon$. 


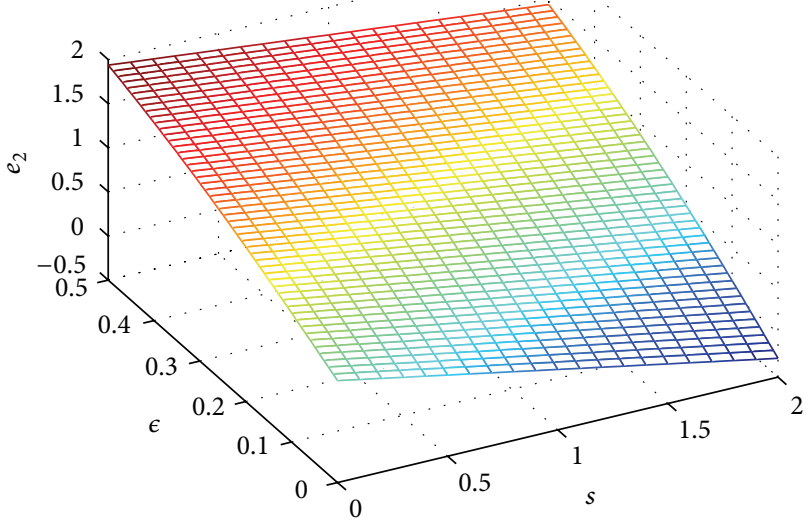

FIGURE 9: $e_{2}$ versus $s$ and $\varepsilon$.

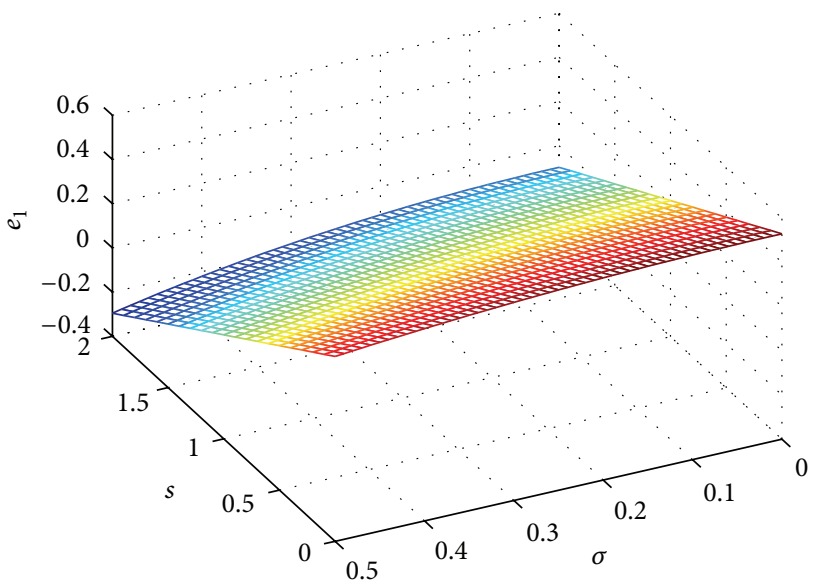

FIGURE 10: $e_{1}$ versus $s$ and $\sigma$.

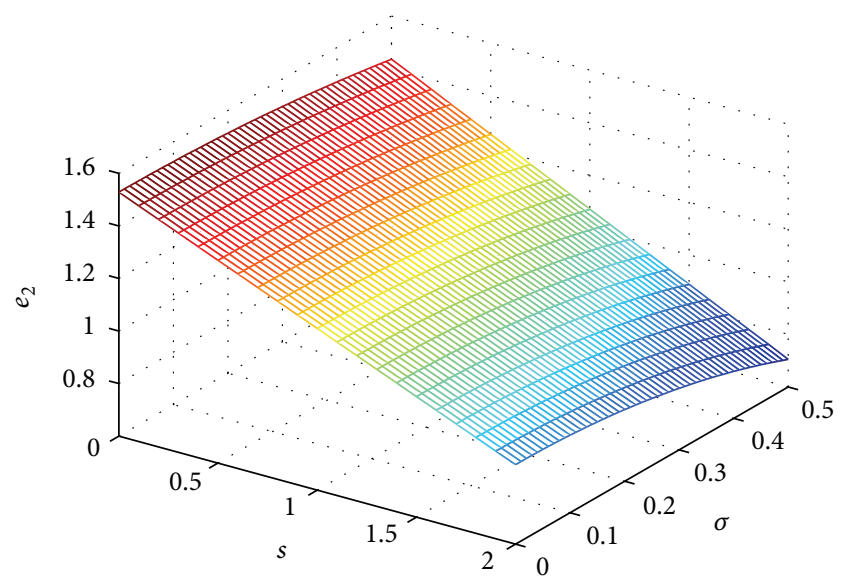

FIGURE 11: $e_{2}$ versus $s$ and $\sigma$.

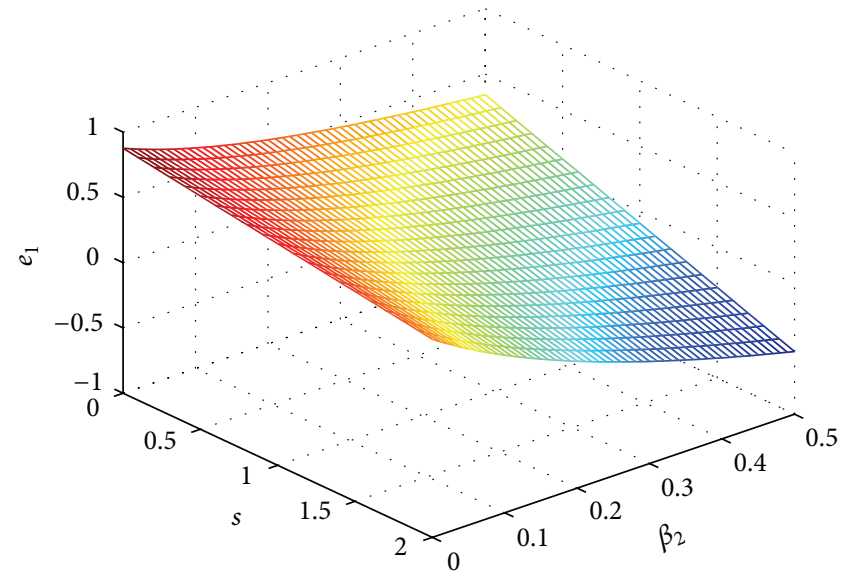

FIGURE 12: $e_{1}$ versus $s$ and $\beta_{2}$.

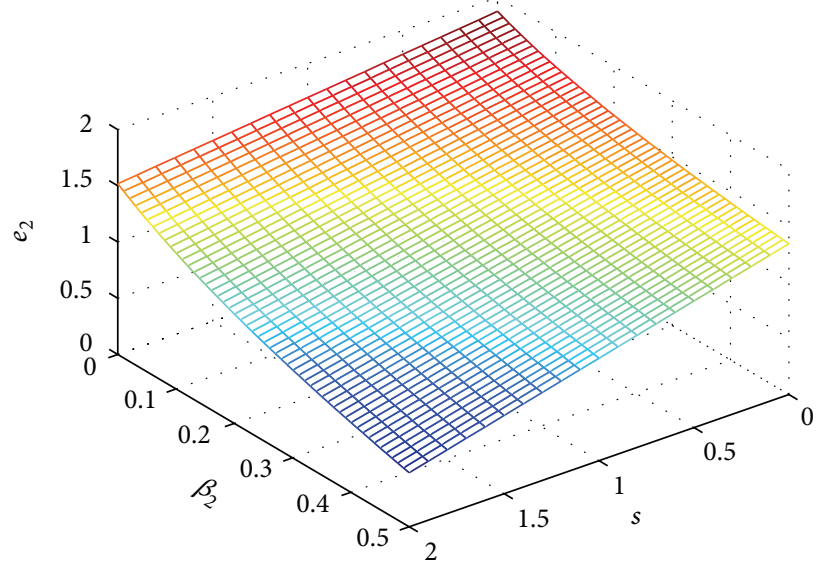

FIGURE 13: $e_{2}$ versus $s$ and $\beta_{2}$.

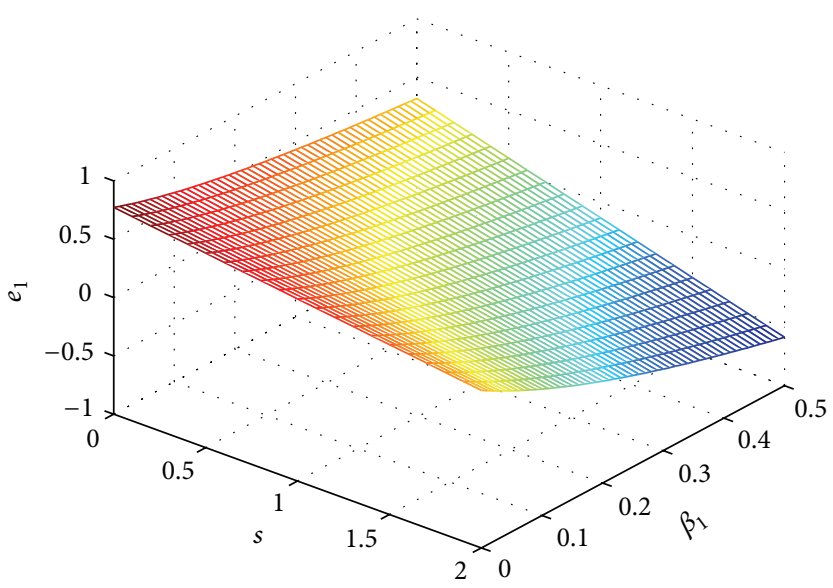

FIGURE 14: $e_{2}$ versus $s$ and $\beta_{1}$. 


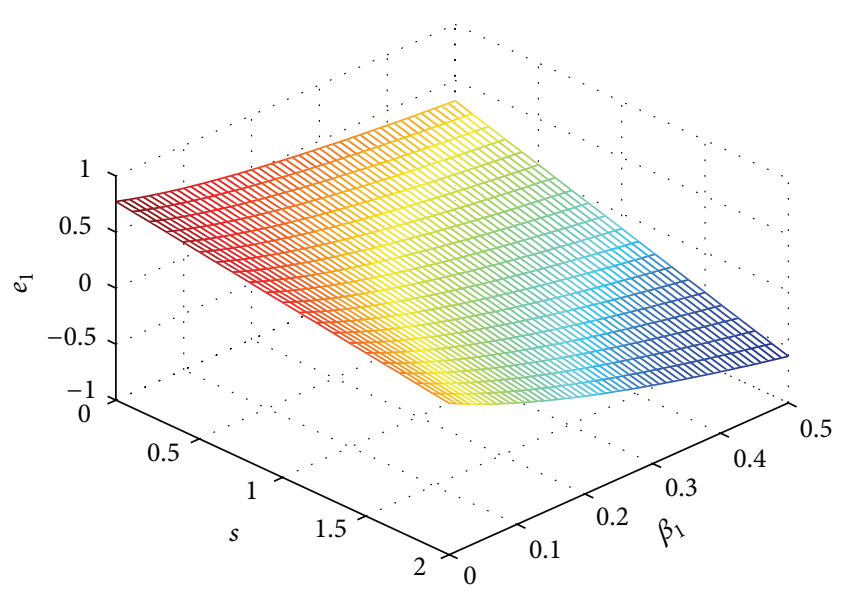

FIGURE 15: $e_{1}$ versus $s$ and $\beta_{1}$.

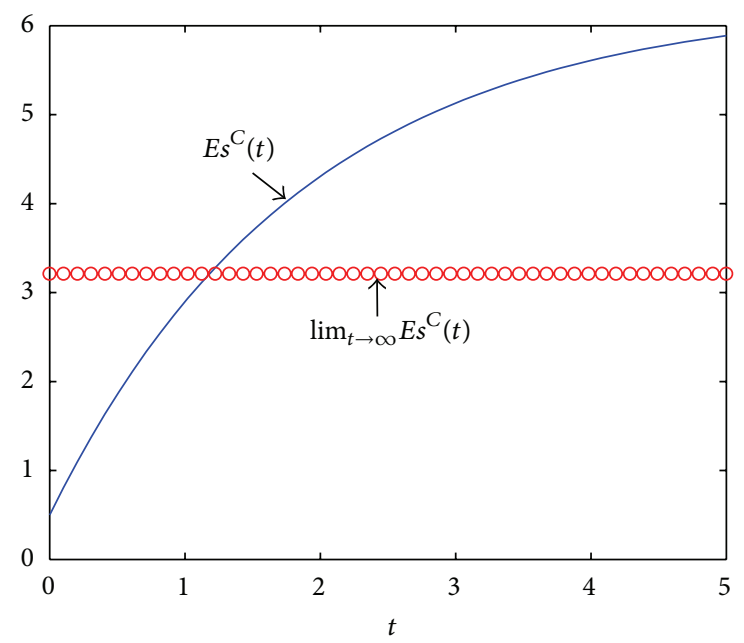

Figure 16: $E s^{C}(t), \lim _{t \rightarrow \infty} E s^{C}(t)$ versus $t$.

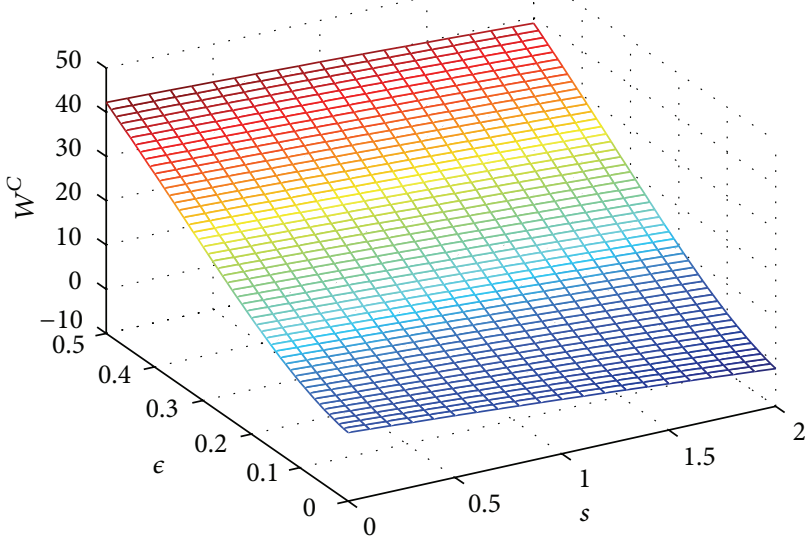

FIGURE 17: $W^{C}(s)$ versus $s$ and $\varepsilon$.

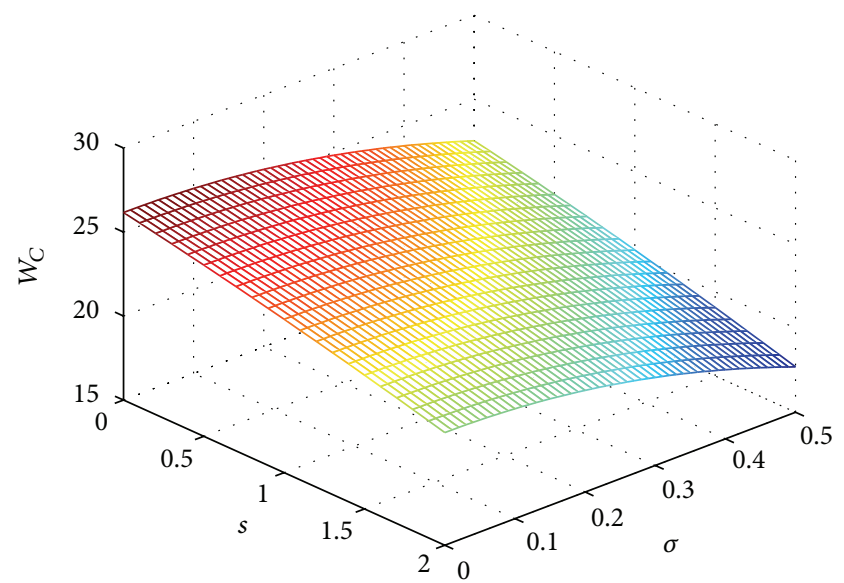

Figure 18: $W^{C}(s)$ versus $s$ and $\sigma$.

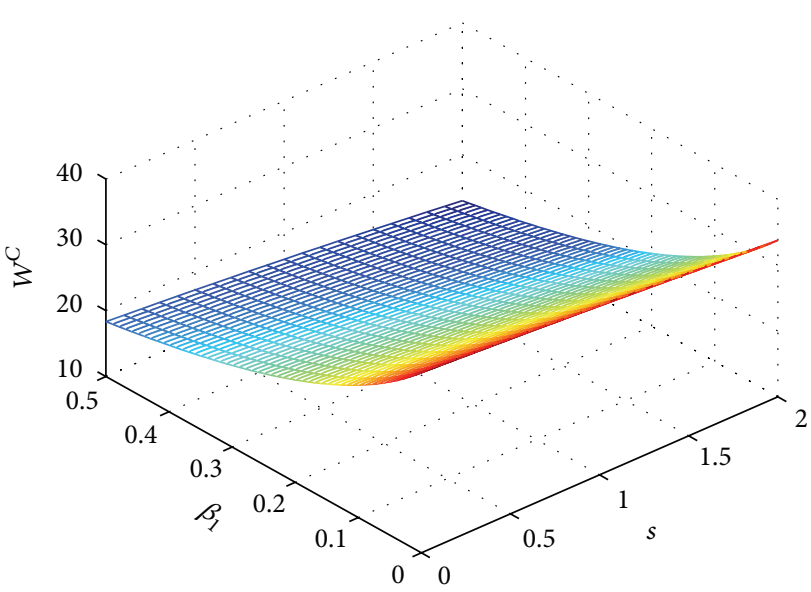

FIgURE 19: $W^{\mathrm{C}}(s)$ versus $s$ and $\beta_{1}$.

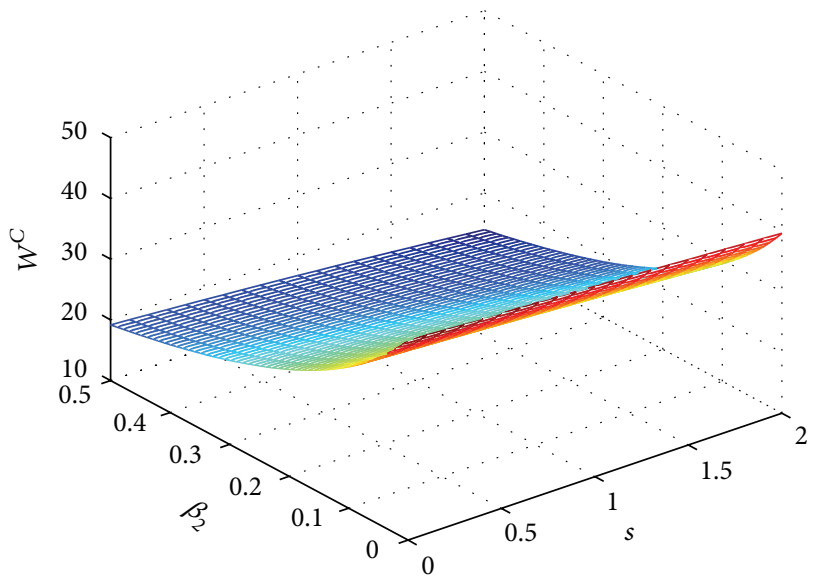

Figure 20: $W^{C}(s)$ versus $s$ and $\beta_{2}$. 
to the natural absorption rate and inversely proportional to the stock of GHGs and constant affected by stochastic factors and cost parameters of player 1 and player 2 . The limitation of GHG stock $\lim _{t \rightarrow \infty} E s^{C}(t)=3.2115$ is shown in Figure 16. For the sake of simplicity, we denote $E W^{C}(s)$ as $W^{C}(s)$ in this section. The whole expected cooperative profit $E W^{C}(s)$ decreases with either $s$ or $\varepsilon$ or $\sigma$ or $\beta_{1}$ or $\beta_{2}$ shown in Figures $17,18,19$, and 20 . In fact, the whole expected cooperative profit is inversely proportional to the natural absorption rate and the stock of GHGs and constant affected by stochastic factors and cost parameters of player 1 and player 2 .

\section{The Distribution of Cooperative Dividend}

We consider the long-term cooperation agreement related to the following crucial questions.

(1) When is a cooperative agreement globally feasible?

(2) In the parameter space where cooperation is achievable, how should the cooperative dividend be distributed among players?

(3) What can ensure that players abide by the cooperative agreement over time?

5.1. Global Feasible Conditions for the Cooperation Agreement. A cooperative agreement is globally feasible if the total cooperative payoff must be greater than the total individual noncooperative payoff. The difference between the two is called the cooperative dividend, which is denoted as DC:

$$
\mathrm{DC}\left(s_{0}\right)=\frac{1}{2}\left(a-A_{2}\right) s_{0}^{2}+\left(b-B_{2}\right) s_{0}+C,
$$

where $C=c-C_{2}-\left(\alpha_{1}^{2} / 2 r\right)=(\mu / 2 r)\left(\mu\left(2 b^{2}-B_{2}^{2}\right)+2\left(\alpha^{1}+\right.\right.$ $\left.\left.\alpha^{2}\right)\left(b-B_{2}\right)\right)$.

Here, $\operatorname{DC}\left(s_{0}\right)$ is a quadratic polynomial of $s_{0}$. Let $\operatorname{DC}\left(s_{0}\right)=0$, one can get

$$
\begin{aligned}
& s_{0}^{-}=\frac{-\left(b-B_{2}\right)-\sqrt{\left(b-B_{2}\right)^{2}-2\left(a-A_{2}\right) C}}{a-A_{2}}, \\
& s_{0}^{+}=\frac{-\left(b-B_{2}\right)+\sqrt{\left(b-B_{2}\right)^{2}-2\left(a-A_{2}\right) C}}{a-A_{2}}
\end{aligned}
$$

for $\left(b-B_{2}\right)^{2}-2\left(a-A_{2}\right) C \geq 0$.

Remark 11. From Definition 1, the discount value of cooperative dividend DC along the optimal trajectory is equal to the cooperative dividend $\mathrm{DC}\left(s_{0}\right)$ in the initial state.

Theorem 12. Let $\beta_{2}^{+}=\beta_{1}+\left(\left(r+2 \varepsilon-\sigma^{2}\right) / \mu\right) \sqrt{\beta_{1}}$.

If $\beta_{2}>\beta_{2}^{+}$, then

$$
D C\left(s_{0}\right) \begin{cases}>0, & \text { if } C \geq 0, \forall s_{0} \geq 0, \\ <0, & \text { if } C<0, s_{0} \in\left[0, s_{0}^{+}\right], \\ >0, & \text { if } C<0, s_{0}>s_{0}^{+} .\end{cases}
$$

If $\beta_{2} \in\left[\beta_{1}, \beta_{2}^{+}\right]$and $b-B_{2}>0$, then

$$
D C\left(s_{0}\right) \begin{cases}>0, & \text { if } C \geq 0, s_{0} \in\left[0, s_{0}^{-}\right], \\ >0, & \text { if } C<0, s_{0} \in\left[s_{0}^{+}, s_{0}^{-}\right] .\end{cases}
$$

If $\beta_{2} \in\left[\beta_{1}, \beta_{2}^{+}\right]$and $b-B_{2}<0$, then $D C\left(s_{0}\right)<0$ for all $s_{0}>0$.

Proof. It is easy to prove it by analyzing the quadratic function $\mathrm{DC}\left(s_{0}\right)=0$ of $s_{0}$.

Remark 13. The above theorem states that the cooperative agreement is achievable if $\mathrm{DC}\left(s_{0}\right)>0$.

5.2. The Distribution Method. Assuming that the cooperation is globally feasible, then it is an important problem for us to tackle and how to allocate $\mathrm{DC}\left(s_{0}\right)$ between two players. From cooperative game or bargaining theory, one can find many solutions to the problems, such as core, Shapley value, Nucleolus, and Nash bargaining solution (NBS).

The NBS method will be applied into this paper. Let $\left(W_{1}^{N}, W_{2}^{N}\right)$ denote the Nash equilibrium, and let $\left(W_{1}^{\mathrm{NBS}}, W_{2}^{\mathrm{NBS}}\right)$ denote the Nash bargaining solution. One can get

$$
\begin{aligned}
W_{1}^{\mathrm{NBS}} & =W_{1}^{N}+\frac{\mathrm{DC}\left(s_{0}\right)}{2} \\
& =W_{1}^{N}+\frac{1}{2}\left(\left(W_{1}^{C}+W_{2}^{C}\right)-\left(W_{1}^{N}+W_{2}^{N}\right)\right), \\
W_{2}^{\mathrm{NBS}} & =W_{2}^{N}+\frac{\mathrm{DC}\left(s_{0}\right)}{2} \\
& =W_{2}^{N}+\frac{1}{2}\left(\left(W_{1}^{C}+W_{2}^{C}\right)-\left(W_{1}^{N}+W_{2}^{N}\right)\right),
\end{aligned}
$$

here

$$
\begin{gathered}
W_{1}^{N}=\max _{e_{1}} E\left\{\int_{0}^{\infty} e^{-r t} R_{1}\left(e_{1}^{N}(t)\right) d t\right\}, \\
W_{2}^{N}=\max _{e_{2}} E\left\{\int_{0}^{\infty} e^{-r t}\left(R_{2}\left(e_{2}^{N}(t)\right)-D_{2}\left(s^{N}(t)\right)\right) d t\right\}, \\
W_{i}^{C}=\max _{e_{i}} E\left\{\int_{0}^{\infty} e^{-r t}\left(R_{i}\left(e_{i}^{N}(t)\right)-D_{i}\left(s^{N}(t)\right)\right) d t\right\}, \\
i=1,2 .
\end{gathered}
$$

Remark 14. (1) For non-cooperation stochastic differential game $\Gamma\left(s_{\tau}, \infty-\tau\right)$, the current value of expected payoff is equal to its subgame value function for the corresponding discount in the state variable $s(t)=s_{t}$ at the interval $[t, \infty)$.

(2) For cooperation stochastic differential game $\Psi\left(s_{\tau}, \infty-\right.$ $\tau)$, the current value of expected payoff is equal to its subgame value function for the corresponding discount in the state variable $s(t)=s_{t}$ at the interval $[t, \infty)$. 
5.3. Abide by the Cooperative Agreement. It is crucial to build a credible basis for abiding strictly by the cooperative agreement in a long time. Inspired by [14, 35, 39, 41-43], we try to design a transfer payment mechanism for subgame consistent agreement based on the Nash bargaining solution.

Denote $W_{i}^{\mathrm{NBS}}\left(s^{C}(t)\right), W_{i}^{N}\left(s^{C}(t)\right)$ as cooperation and noncooperative distribution, respectively.

Definition 15 (see [29]). $\left(W_{1}^{\mathrm{NBS}}\left(s^{\mathrm{C}}(t)\right), W_{2}^{\mathrm{NBS}}\left(s^{\mathrm{C}}(t)\right)\right)$ is an effective distribution if it satisfies the following:

(1) $\left(W_{1}^{\mathrm{NBS}}\left(s^{\mathrm{C}}(t)\right), W_{2}^{\mathrm{NBS}}\left(s^{\mathrm{C}}(t)\right)\right)$ is a Pareto optimal distribution,

(2) $W_{i}^{\mathrm{NBS}}\left(s^{C}(t)\right) \geq W_{i}^{N}\left(s^{C}(t)\right), i=1,2$,

where $s^{C}(t)$ is state trajectory of the cooperative state trajectory.

Definition 16 (see [29]). ( $\left.W_{1}^{\mathrm{NBS}}\left(s^{\mathrm{C}}(t)\right), W_{2}^{\mathrm{NBS}}\left(s^{\mathrm{C}}(t)\right)\right)$ is a subgame consistent distribution if it satisfies

(1) $\left(W_{1}^{\mathrm{NBS}}\left(s^{\mathrm{C}}(t)\right), W_{2}^{\mathrm{NBS}}\left(s^{\mathrm{C}}(t)\right)\right)$ is a Pareto optimal distribution,

(2) $W_{i}^{\mathrm{NBS}}\left(s^{\mathrm{C}}(t)\right) \geq W_{i}^{N}\left(s^{C}(t)\right), i=1,2$ for $t \in[\tau, \infty)$,

where $s^{C}(t)$ is state trajectory of the cooperation state trajectory.

Denote $\xi_{i}(t), i=1,2$ instantaneous payoff-distribution procedure of the subgame, which satisfies

$$
\begin{array}{r}
\int_{0}^{\infty} e^{-r t} \xi_{i}(t) d t=W_{i}^{\mathrm{NBS}}\left(s_{0}\right), \quad i=1,2 . \\
W_{i}^{\mathrm{NBS}}\left(s_{0}\right)=\int_{0}^{t} e^{-r \tau} \xi_{i}(\tau) d \tau+e^{-r t} W_{i}^{\mathrm{NBS}}\left({ }^{C}(t)\right), \\
i=1,2,
\end{array}
$$

where

$$
\begin{array}{r}
W_{i}^{\mathrm{NBS}}\left(s^{\mathrm{C}}(t)\right) \\
=W_{i}^{N}\left(s^{C}(t)\right)+\frac{1}{2} \sum_{i=1}^{2}\left(W_{i}^{C}\left(s^{C}(t)\right)-W_{i}^{N}\left(s^{C}(t)\right)\right), \\
i=1,2 .
\end{array}
$$

For the sake of simplicity, let $s^{C}(t)$ denote $E s^{C}(t)$, and let $\Gamma\left(s^{C}(t)\right)$ denote a subgame in state $s_{t}^{C}=s^{C}(t)$. If a cooperative agreement is feasible in the subgame, player $i, i=1,2$ can get a Nash bargaining solution from (43).

Differential (43) with respect to $t$, one has

$$
\xi_{i}(t)=r W_{i}^{\mathrm{NBS}}\left(s^{C}(t)\right)-\frac{d}{d t}\left(W_{i}^{\mathrm{NBS}}\left(s^{C}(t)\right)\right), \quad i=1,2 .
$$

Equation (45) shows that the instantaneous payoff of player $i$ in the time $t$ is equal to its interest payoff minus the ratio of Nash bargaining solution.
Remark 17. If (45) is multiplied by discount factor $e^{-r t}$, by integrating both sides, one can get

$$
\begin{aligned}
\int_{0}^{\infty} & e^{-r t} \xi_{i}(t) d t \\
& =\int_{0}^{\infty}\left(r e^{-r t} W_{i}^{\mathrm{NBS}}\left(s^{C}(t)\right)-e^{-r t} \frac{d}{d t}\left(W_{i}^{\mathrm{NBS}}\left(s^{C}(t)\right)\right)\right) d t \\
& =-\left.e^{-r t} W_{i}^{\mathrm{NBS}}\left(s^{C}(t)\right)\right|_{0} ^{\infty}=W_{i}^{\mathrm{NBS}}\left(s^{C}(0)\right) \\
& =W_{i}^{\mathrm{NBS}}\left(s_{0}\right), \quad i=1,2, \\
W_{i}^{\mathrm{NBS}} & \left(s^{C}(t)\right)-W_{i}^{\mathrm{N}}\left(s^{C}(t)\right) \\
& =\frac{1}{2} \sum_{i=1}^{2}\left(W_{i}^{\mathrm{C}}\left(s^{C}(t)\right)-W_{i}^{N}\left(s^{C}(t)\right)\right) \\
& =\frac{1}{2} \mathrm{DC}\left(s^{C}(t)\right), \quad i=1,2,
\end{aligned}
$$

where

$$
\begin{aligned}
\operatorname{DC} & \left(s^{C}(t)\right) \\
= & \sum_{i=1}^{2}\left(W_{i}^{C}\left(s^{C}(t)\right)-W_{i}^{N}\left(s^{C}(t)\right)\right) \\
= & \frac{1}{2}\left(a-A_{2}\right)\left(s^{C}(t)\right)^{2}+\left(b-B_{2}\right) s^{C}(t)+C \geq 0 .
\end{aligned}
$$

Hence, $W_{i}^{\mathrm{NBS}}\left(s^{C}(t)\right)-W_{i}^{N}\left(s^{C}(t)\right), i=1,2$ has the same sign as $(1 / 2) \operatorname{DC}\left(s^{C}(t)\right)$.

In fact, if $\mathrm{DC}\left(s_{0}\right)<0$, the cooperative game will not be played. So the next section will discuss the conditions of $\mathrm{DC}\left(s_{0}\right) \geq 0$.

\subsection{Sufficient Conditions for $D C\left(s^{C}(t)\right) \geq 0$}

Theorem 18. If the cooperative solution is interior, and $D C\left(s^{C}(t)\right)$ is increasing for $D C\left(s_{0}\right)>0, D C\left(s^{C}(t)\right) \geq 0$ for all $t \in[0, \infty)$ holds.

Proof. If for all $t \in[0, \infty)$, then $s^{C}(t)>s_{0}$, that is, the theorem is proved.

Next we prove $s^{C}(t)>s_{0}$.

From (34), one can have

$$
s^{C}(t)-s_{0}=\left(e^{\left(2 \mu^{2} a^{2}-\varepsilon\right) t}-1\right)\left(\frac{\mu \alpha_{1}+\mu \alpha_{2}+2 \mu^{2} b}{2 \mu^{2} a^{2}-\varepsilon}-s_{0}\right) .
$$

Since the GHG cooperative emission is interior, and $e_{i}^{C}=\alpha_{i}+$ $\mu(a s+b), i=1,2$, one can get $\alpha_{i}+\mu b>-\mu a s>0, i=1,2$, so $\left(\mu \alpha_{1}+\mu \alpha_{2}+2 \mu^{2} b\right) /\left(2 \mu^{2} a^{2}-\varepsilon\right)<0$.

According to $a<0$ and $e^{\left(2 \mu^{2} a^{2}-\varepsilon\right) t}-1<0, s^{C}(t)>s_{0}$ holds. It is proved. 
From (45), one can get the instantaneous payoff $\xi_{i}(t), i=$ 1,2 as follows:

$$
\begin{aligned}
& \xi_{1}(t)=\frac{1}{2} r A_{1} \\
&+ \frac{1}{2}\left(r\left(\frac{1}{2} a s^{2}+b s+c\right)\right. \\
&\left.-(a s+b)\left(\mu\left(e_{1}+e_{2}\right)-\varepsilon s\right)-\frac{1}{2} a \sigma^{2}\right) \\
&-\frac{1}{2}( r\left(\frac{1}{2} A_{2} s^{2}+B_{2} s+C_{2}\right) \\
&\left.-\left(A_{2} s+B_{2}\right)\left(\mu\left(e_{1}+e_{2}\right)-\varepsilon s\right)-\frac{1}{2} A_{2} \sigma^{2}\right), \\
& \xi_{2}(t)=\frac{1}{2}\left(r\left(\frac{1}{2} A_{2} s^{2}+B_{2} s+C_{2}\right)\right. \\
&\left.\quad-\left(A_{2} s+B_{2}\right)\left(\mu\left(e_{1}+e_{2}\right)-\varepsilon s\right)-\frac{1}{2} A_{2} \sigma^{2}\right) \\
&+\frac{1}{2}\left(r\left(\frac{1}{2} a s^{2}+b s+c\right)-(a s+b)\right. \\
&\left.\quad \times\left(\mu\left(e_{1}+e_{2}\right)-\varepsilon s\right)-\frac{1}{2} a \sigma^{2}\right)-\frac{1}{2} r A_{1} .
\end{aligned}
$$

\section{Conclusion}

Taking the effect of uncertainty into consideration, we use stochastic differential game to build cooperative and noncooperative game model for global GHG emission between developing and developed countries. Then we calculate the feedback Nash equilibrium and the Pareto optimal solution, give the globally feasible and sustainable conditions of the cooperative agreement, and propose the distribution method of payoff. At last, we illustrate the above results by numerical simulations. These results show that developing and developed countries would rationally adopt the Nash equilibrium as their GHGs emissions Pareto optimal solution in the long term.

\section{Acknowledgments}

This work is supported partly by Excellent Young Scientist Foundation of Shandong Province (Grant no. BS2011SF018), National Social Science Foundation of China (Grant no. 12BJY103), Humanities and Social Sciences Foundation of the Ministry of Education of China (Grant no. 11YJCZH200), and National Natural Science Foundation of China (Grant no. 71272148).

\section{References}

[1] J. H. Williams, A. DeBenedictis, R. Ghanadan et al., "The technology path to deep greenhouse gas emissions cuts by 2050: the pivotal role of electricity," Science, vol. 335, pp. 53-59, 2012.
[2] S. Bastianoni, F. M. Pulselli, and E. Tiezzi, "The problem of assigning responsibility for greenhouse gas emissions," Ecological Economics, vol. 49, no. 3, pp. 253-257, 2004.

[3] W. Parton, S. DelGrosso, E. Marx, and A. Swan, "Agriculture’s role in cutting greenhouse gas emissions," Issues in Science and Technology, vol. 27, pp. 29-32, 2011.

[4] R. S. J. Tol, “The marginal costs of greenhouse gas emissions," Energy Journal, vol. 20, no. 1, pp. 61-81, 1999.

[5] A. Ansuategi and M. Escapa, "Economic growth and greenhouse gas emissions," Ecological Economics, vol. 40, no. 1, pp. 23-37, 2002.

[6] F. van der Ploeg and A. de Zeeuw, "A differential game of international pollution control," Systems \& Control Letters, vol. 17, no. 6, pp. 409-414, 1991.

[7] F. van der Ploeg and A. J. de Zeeuw, "International aspects of pollution control," Environmental \& Resource Economics, vol. 2, no. 2, pp. 117-139, 1992.

[8] N. V. Long, "Pollution control: a differential game approach," Annals of Operations Research, vol. 37, no. 1-4, pp. 283-296, 1992.

[9] S. J. Rubio and B. Casino, "A note on cooperative versus non-cooperative strategies in international pollution control," Resource and Energy Economics, vol. 24, no. 3, pp. 251-261, 2002.

[10] D. W. K. Yeung, "Dynamically consistent cooperative solution in a differential game of transboundary industrial pollution," Journal of Optimization Theory and Applications, vol. 134, no. 1, pp. 143-160, 2007.

[11] O. Bahn and A. Haurie, "A class of games with coupled constraints to model international GHG emission agreements," International Game Theory Review, vol. 10, no. 4, pp. 337-362, 2008.

[12] S. Jørgensen, G. Martín-Herrán, and G. Zaccour, "Agreeability and time consistency in linear-state differential games," Journal of Optimization Theory and Applications, vol. 119, no. 1, pp. 4963, 2003.

[13] S. Jørgensen, G. Martín-Herrán, and G. Zaccour, "Sustainability of cooperation overtime in linear-quadratic differential games," International Game Theory Review, vol. 7, no. 4, pp. 395-406, 2005.

[14] S. Jørgensen and G. Zaccour, "Time consistent side payments in a dynamic game of downstream pollution," Journal of Economic Dynamics \& Control, vol. 25, no. 12, pp. 1973-1987, 2001.

[15] P. Smala Fanokoa, I. Telahigue, and G. Zaccour, "Buying cooperation in an asymmetric environmental differential game," Journal of Economic Dynamics \& Control, vol. 35, no. 6, pp. 935946, 2011.

[16] M. Breton, G. Martín-Herrán, and G. Zaccour, "Equilibrium investment strategies in foreign environmental projects," Journal of Optimization Theory and Applications, vol. 130, no. 1, pp. 23-40, 2006.

[17] M. Breton, G. Zaccour, and M. Zahaf, "A differential game of joint implementation of environmental projects," Automatica, vol. 41, no. 10, pp. 1737-1749, 2005.

[18] M. Breton, G. Zaccour, and M. Zahaf, "A game-theoretic formulation of joint implementation of environmental projects," European Journal of Operational Research, vol. 168, no. 1, pp. 221-239, 2005.

[19] L. Petrosjan and G. Zaccour, "Time-consistent Shapley value allocation of pollution cost reduction," Journal of Economic Dynamics \& Control, vol. 27, no. 3, pp. 381-398, 2003. 
[20] E. J. Dockner, S. Jørgensen, N. V. Long, and G. Sorger, Differential Games in Economics and Management Science, Cambridge University Press, Cambridge, UK, 2000.

[21] S. M. J. Mirzapour Al-E-Hashem, A. Baboli, S. J. Sadjadi, and M. B. Aryanezhad, "A multiobjective stochastic productiondistribution planning problem in an uncertain environment considering risk and workers productivity," Mathematical Problems in Engineering, vol. 2011, Article ID 406398, 14 pages, 2011.

[22] X.-J. Xie, N. Duan, and X. Yu, "State-feedback control of high-order stochastic nonlinear systems with SiISS inverse dynamics," Institute of Electrical and Electronics Engineers, vol. 56, no. 8, pp. 1921-1926, 2011.

[23] X.-J. Xie and L. Liu, "Further results on output feedback stabilization for stochastic high-order nonlinear systems with time-varying delay," Automatica, vol. 48, no. 10, pp. 2577-2586, 2012.

[24] J. Yin, S. Khoo, Z. Man, and X. Yu, "Finite-time stability and instability of stochastic nonlinear systems," Automatica, vol. 47, no. 12, pp. 2671-2677, 2011.

[25] W. Zhang, Y. Huang, and H. Zhang, "Stochastic H-2/H-infinity control for discrete-time systems with state and disturbance dependent noise," Automatica, vol. 43, no. 3, pp. 513-521, 2007.

[26] H. Ma, W. Zhang, and T. Hou, "Infinite horizon H-2/H-infinity control for discrete-time time-varying Markov jump systems with multiplicative noise," Automatica, vol. 48, no. 7, pp. 14471454, 2012.

[27] W. Li, Y. Jing, and S. Zhang, "State feedback control of a class of high-order stochastic nonlinear systems," International Journal of Robust and Nonlinear Control, vol. 22, no. 14, pp. 1583-1601, 2012.

[28] W. Li, X. Liu, and S. Zhang, "Further results on adaptive state-feedback stabilization for stochastic high-order nonlinear systems," Automatica, vol. 48, no. 8, pp. 1667-1675, 2012.

[29] S. Mataramvura and B. Øksendal, "Risk minimizing portfolios and HJBI equations for stochastic differential games," Stochastica, vol. 80, no. 4, pp. 317-337, 2008.

[30] G. Wang and Z. Yu, "A partial information non-zero sum differential game of backward stochastic differential equations with applications," Automatica, vol. 48, no. 2, pp. 342-352, 2012.

[31] X. Zhao, G. Ren, C. Fan, and C. Ding, "A simulation-based dynamic stochastic route choice model for evacuation," Mathematical Problems in Engineering, vol. 2012, Article ID 396248, 18 pages, 2012.

[32] C. Lodi, P. Bacher, J. Cipriano, and Madsen, "Modelling the heat dynamics of a monitored test reference environment for building integrated photovoltaic systems using stochastic differential equations," Energy and Buildings, vol. 50, pp. 273281, 2012.

[33] A. Kopp, I. Büsching, R. D. Strauss, and M. S. Potgieter, "A stochastic differential equation code for multidimensional Fokker-Planck type problems," Computer Physics Communications, vol. 183, no. 3, pp. 530-542, 2012.

[34] C. K. Leong and W. Huang, "A stochastic differential game of capitalism," Journal of Mathematical Economics, vol. 46, no. 4, pp. 552-561, 2010.

[35] D. W. K. Yeung and L. A. Petrosyan, "A cooperative stochastic differential game of transboundary industrial pollution," Automatica, vol. 44, no. 6, pp. 1532-1544, 2008.

[36] W.-K. Wang and C.-O. Ewald, "A stochastic differential fishery game for a two species fish population with ecological interaction," Journal of Economic Dynamics \& Control, vol. 34, no. 5, pp. 844-857, 2010.
[37] M. Taksar and X. Zeng, "Optimal non-proportional reinsurance control and stochastic differential games," Insurance, vol. 48, no. 1, pp. 64-71, 2011.

[38] B. Xin and T. Chen, "On a master-slave Bertrand game model," Economic Modelling, vol. 28, no. 4, pp. 1864-1870, 2011.

[39] D. W. K. Yeung and L. A. Petrosyan, Cooperative Stochastic Differential Games, Springer, New York, NY, USA, 2006.

[40] C.-O. Ewald and W.-K. Wang, "Analytic solutions for infinite horizon stochastic optimal control problems via finite horizon approximation: a practical guide," Mathematical Social Sciences, vol. 61, no. 3, pp. 146-151, 2011.

[41] B. Tolwinski, A. Haurie, and G. Leitmann, "Cooperative equilibria in differential games," Journal of Mathematical Analysis and Applications, vol. 119, no. 1-2, pp. 182-202, 1986.

[42] M. Germain and V. Van Steenberghe, "Constraining equitable allocations of tradable $\mathrm{CO}_{2}$ emission quotas by acceptability," Environmental and Resource Economics, vol. 26, no. 3, pp. 469492, 2003.

[43] D. W. K. Yeung and L. A. Petrosyan, "Subgame consistent cooperative solutions in stochastic differential games," Journal of Optimization Theory and Applications, vol. 120, no. 3, pp. 651666, 2004. 


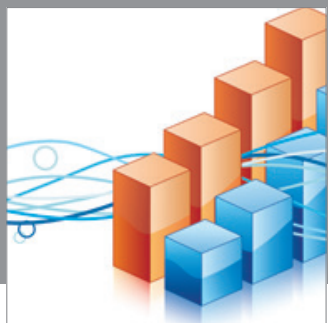

Advances in

Operations Research

mansans

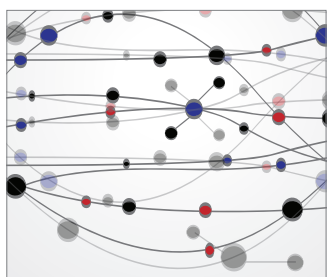

The Scientific World Journal
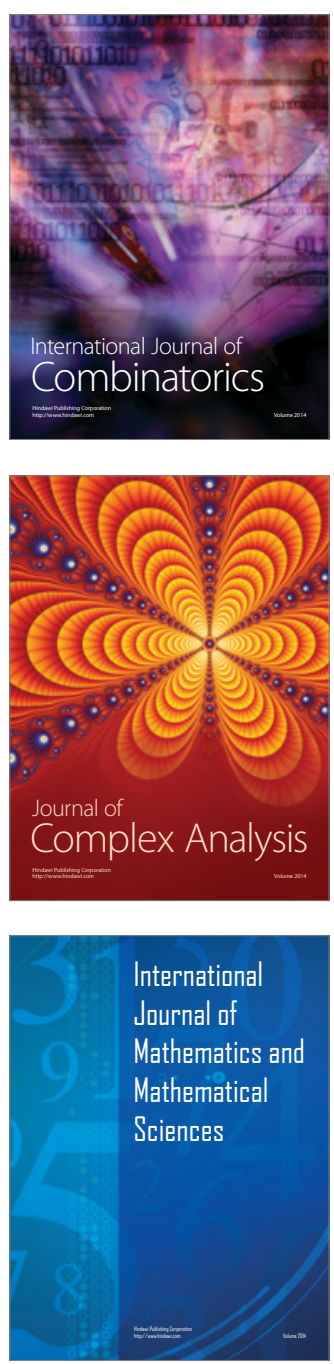
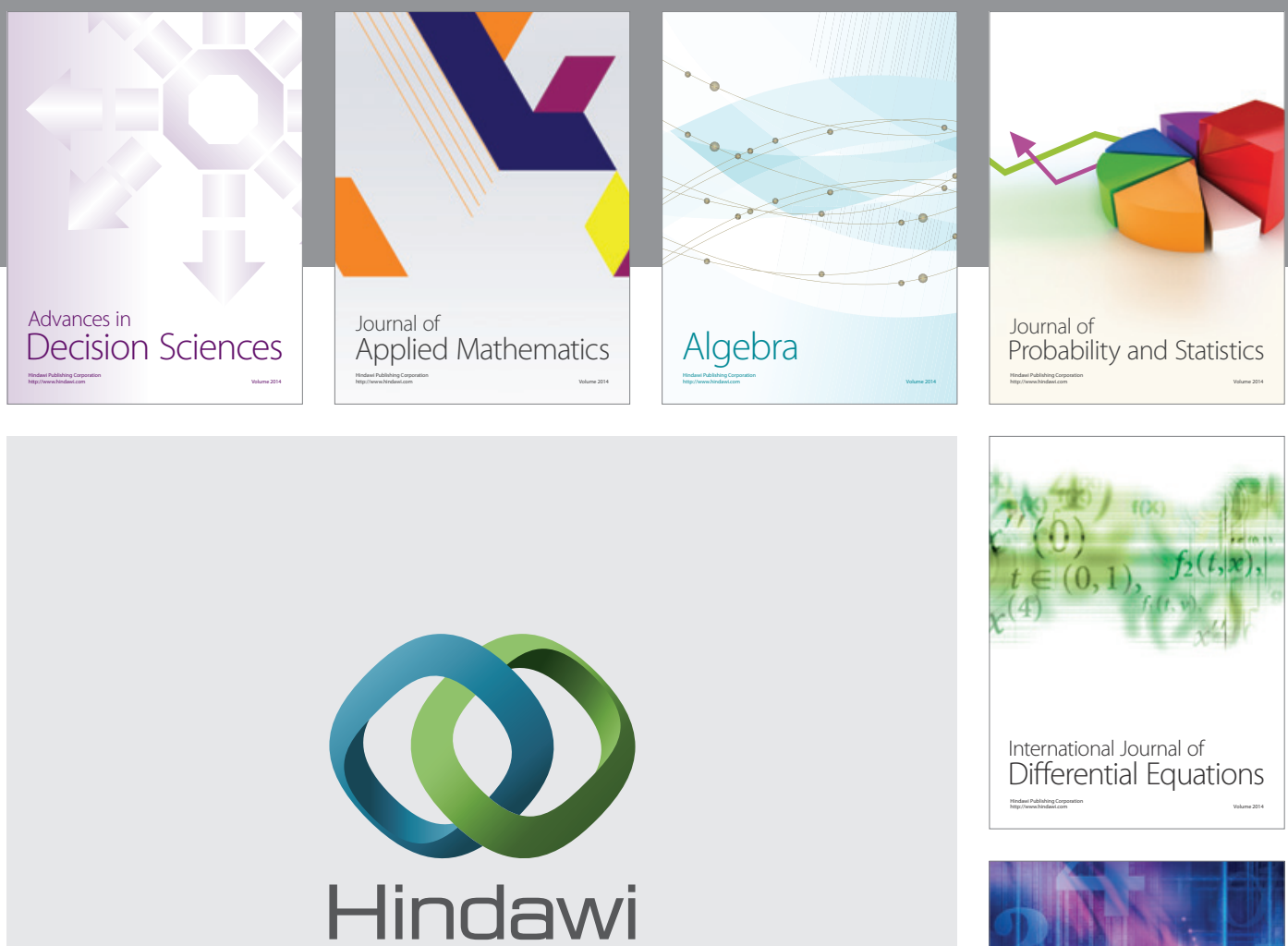

Submit your manuscripts at http://www.hindawi.com
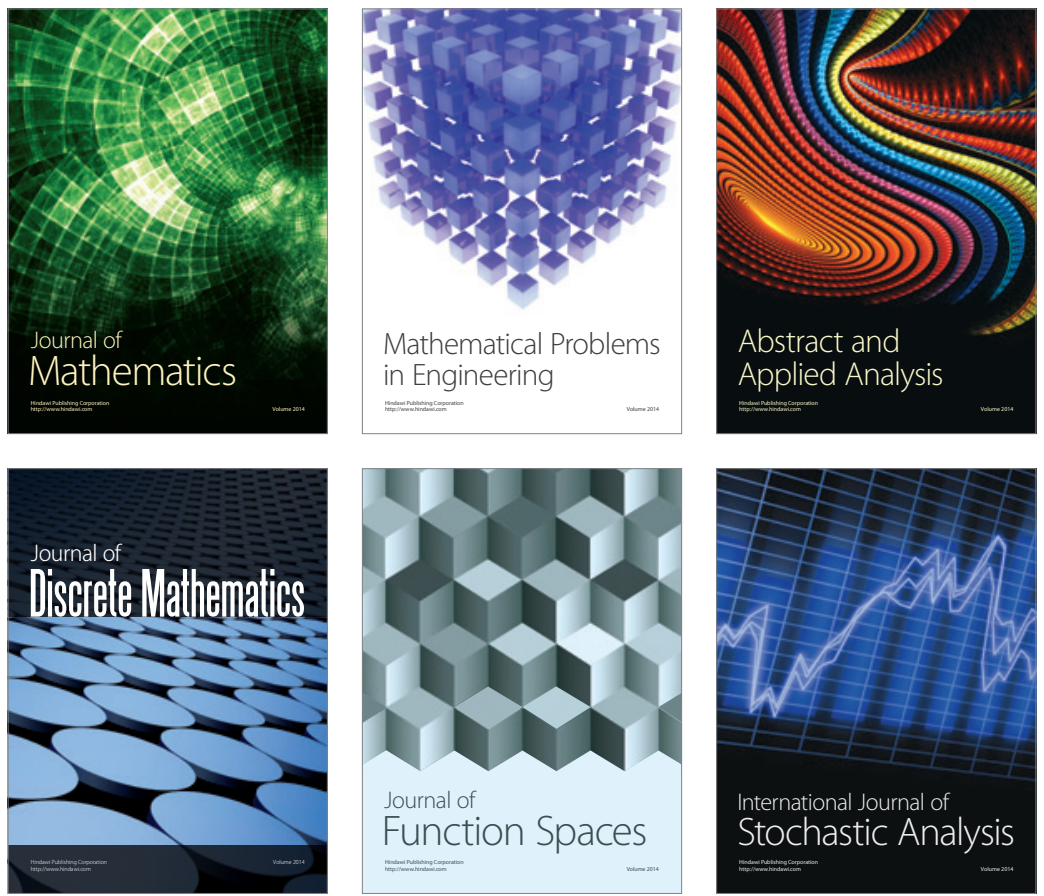

Journal of

Function Spaces

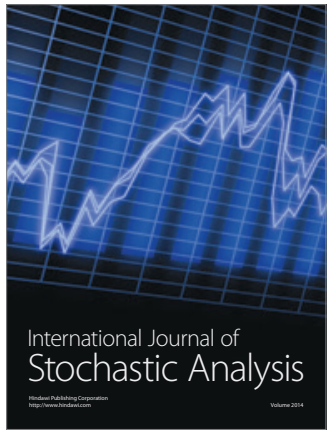

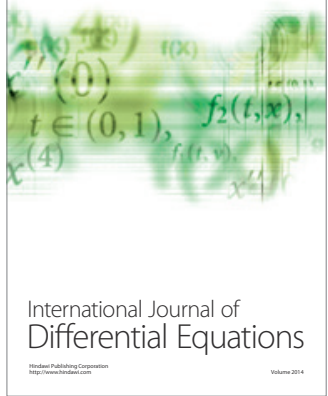
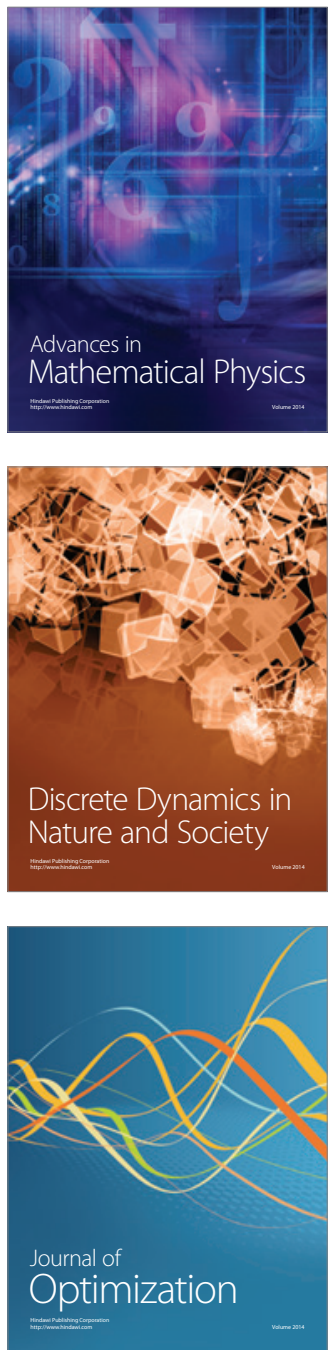